\title{
A Genre-based Analysis of Brief Tourist Information Texts
}

\author{
Shuang Huang \\ School of Foreign Languages and Cultures, Beijing Wuzi University, Beijing, China \\ huangshuang@bwu.edu.cn
}

Keywords: brief tourist information text, genre, move analysis, destination image

\begin{abstract}
This present study gives a genre-based analysis of 30 BTI texts on websites of tourism destinations. The study first identifies the moves and steps of the corpus employing Swales' top-down move analysis model (1990) and then examines the linguistic forms to realize each move. Applying ideas from destination image, this study further explores how the image is discursively created and projected. The main findings yielded from the analysis demonstrate that Establishing credentials move as the obligatory move in BTI texts mainly builds the designative and evaluative images of tourism destinations, which induce the affective image.
\end{abstract}

\section{Introduction}

Brief tourist information text is a pre-trip tourism text delivering travel information about a tourist attraction or destination. As an important promotional device in tourism industry, this genre has found its way into the websites of many local tourism organizations or companies, which aim to promote the tourism potential of their region. Varying in sophistication from a few simple pages depicting the area to fully clickable interactive sites showing various images and volumes of information, these websites set their role to that of information, promotion and appetite whetting, with the point to persuade the reader to leave his computer screen and go to the place in person (Dicks, 2007). On the other hand, tourists nowadays especially self-styled travelers are shifting to web-based resources including travel websites and blogs from traditional printed materials for information about attractions, flights, and hotels, etc. (Thurlow \& Jaworski, 2010).

Despite the modern emphasis on the visual aspects of online promotion, brief tourist information (hereafter BTI) text, as a tourism publicity literature, is believed to be able to perform an important function in the decision-making process which draws people to a tourism destination. The term "brief tourist information" text originated from the genre study of Henry and Roseberry (1996). In the present study, the online BTI text refers to the written text focusing on one destination that often appears in the column "about us" or on the first page of the website of a tourism destination.

This study aims to conduct a genre-based analysis of English BTI texts by examining the move structures at macro-level, typical linguistic choices at micro-level as well as the discursive construction of destination image.

\section{Theoretical background and methodology}

The present study is based on the genre theory and English for Specific Purposes (ESP) approach to genre analysis as well as the concept of destination image.

Genre and ESP approach. The notion of genre designates a distinctive category of discourse of any type, spoken or written, with or without literary aspirations, including academic and professional discourses and other everyday types of discourse. ESP researchers understand genre as 
a collection of communicative events or textual practices with their identifiable central purposes, their prototypical content and conventionalized form, developed and recognized by the members of a specific discourse community, based on contextual, social and cognitive regularities.

The characteristics of genre can be summarized as follows: Firstly, genre is goal-oriented but the communicative purpose is unstable; secondly, genre is not static but a dynamic process; thirdly, genre, staged with typified constituent segments, is eventually realized through lexico-grammatical devices (Lin \& Yang, 2007).

Genre is a formal property of texts, and this attribute enables them to be described as a sequence of segments, or "moves", each of which represents a stretch of text shaped and constrained by a particular communicative function and contributes in some way to serving the more global and general communicative purpose of the genre as a whole. It is a discourse unit used in research describing the generic structure of a genre. Made up of a bundle of linguistic features, a move has a uniform orientation and signals the content of discourse through lexical meanings, prepositional meanings, or illocutionary forces, etc. The unique structure of the moves of a particular genre gives its identity and distinguishes it from other ones.

Each move embodies a series of constituent components, which combine to contain information in the move. These discourse segments subordinate to move are referred to as "steps" by Swales (1990). Bhatia (1993) set out that moves are discriminative elements of generic organization while steps are non-discriminative options within the allowable contributions available to an addresser for creative or innovative genre constructing.

Swales (1990) built his three-move schema Create a Research Space (CARS) model for research article introductions. He identified the following Moves: Establishing a territory, Establishing a niche, and Occupying the niche. Serving the writer's specific social purposes, each move can be realized by a certain number of steps in a particular sequential order.

Destination image. Tourism destination image refers to the holistic impression tourists have of a destination. As a complex concept, destination image can be divided into projected image and perceived image (Baloglu \& McCleary, 1999). Projected image is the image that the destination expects to create, while perceived image is the tourist's subjective impression of the destination (Zhang, Xu, Lu \& Lei, 2015). Projected image is perceived as an important source of perceived image. Destinations attract potential tourists by ways of broadcasting positive projected image, anticipating that the same perceived image, as the projected image, can be built in tourists. Thanks to global availability of the Internet access, websites of tourism destinations are now so well developed as a mainstream mass communication medium for delivering selected information, infiltrating projected destination image and promoting tourist products and services.

Either projected image or perceived image can be studied in terms of designative image and appraisive image. According to Richards and Wilson (2004), the designative component is concerned with categorization of cognitive elements of the physical properties of a place. For instance, cultural resources, such as modern architecture, museums, and events, in an urban destination, constitute designative urban destination images (Zhang, Xu, Lu \& Lei, 2015). The appraisive component is mainly concerning feelings, emotions, values, and meanings, or what is 'felt' about a place, often realized by evaluative descriptions or expressions (e.g., beautiful, romantic) and emotional reactions (e.g., enjoy, relaxed). Accordingly, appraisive image includes evaluative and affective components; the former refers to the reasoned interpretation of designative image, while the latter is an individual's emotional response (Richards \& Wilson, 2004). Designative image is the basis of appraisive image.

Based on the above category of destination image, the current study analyzed how the 
destination image is projected by BTI texts within each structural move and linguistically realized.

Methodology. The focus of the study is on a selection of 30 BTI texts from the official or professional websites of tourism destinations with various subjects ranging from culture landscape, artificialized natural landscape (e.g. gardens, parks, etc.) to natural scenery. The sources of these texts are presented in Appendix 1. Each of the texts in this study focuses on introducing and promoting one tourism destination. The tourism destinations were chosen due to their high impact factor. 15 are World Heritage Sites approved by the United Nations Educational, Scientific and Cultural Organization.

Tourism promotion discourses such as tour booklets, travel guides and tourism websites have been researched on destination projected image. This study depended on qualitative content analysis, which was adopted to describe the original materials. To explore the links between generic structures and destination image, the move types in each text were first identified based on qualitative judgments about the communicative purposes of the components of the text; and then the linguistic realizations of each move were investigated. Meanwhile, the destination images projected by each move were examined.

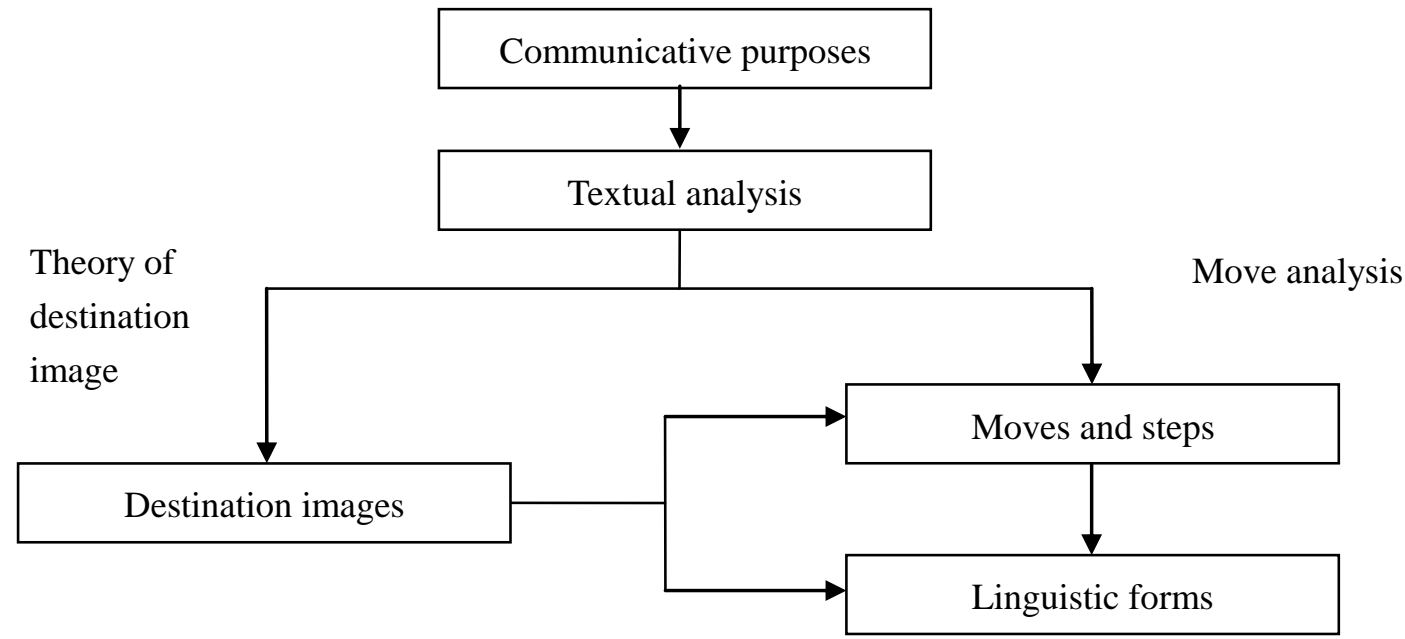

Figure 1. Analytical procedure of the study

The analytical procedure of the study is shown in Figure 1. Textual analysis was done on two particular aspects: destination image and generic structures. As an integral and influential part of potential tourists' decision process, destination image is created by BTI texts to fulfill some particular communicative functions. The creation of an image is concerned with the discursive processes developing from the linguistically defined personalities of a destination. Hence, carrying out an exploration of destination image is assumed to be essential and enlightening. Furthermore, various layers of a genre in Swales' top-down approach (1990) of move analysis are presented. The moves and steps were identified and analyzed and then an overall structure was put forward. The linguistic forms that realize each move were also analyzed.

\section{Major Findings}

The findings are reported and discussed in the following sections.

Communicative purpose. The communicative purpose of BTI texts lies in three aspects: to offer information, to attract attention and to persuade.

The function of informing is considered the first and foremost requirement for BTI text. To give the reader a general idea about his trip, adequate and truthful information needs to be offered about what a tourism destination is like, where it is located geographically, what special and 
distinguished features it possesses, etc., since these elements constitute the major knowledge of the tourist product that concerns the potential tourists most. The knowledge then builds an image of the tourism destination in the reader's mind.

Another communicative purpose is to capture the reader's attention. Being attractive depends on the way the message is conveyed and the elegance or wit of the language. When potential tourists read tourism publicity materials, it is probable that what he reads is confined to the texts he is interested in and those parts that cannot generate his emotional appreciation are likely to be skipped.

As a peripheral member of promotional genres, BTI text may not appear to be exactly advertisement but nevertheless has a strong promotional dimension. In addition to publicizing adequate information and arousing the reader's attention, the ultimate goal of BTI text is to persuade the readers to visit the particular place of tourist attraction being described. This persuasion purpose is target-reader-oriented, which is meant to whet the reader's appetite for travel, convince him of worthiness of visiting, and help turn his appetite into action. As Henry and Roseberry (1996) argued, the overt purpose of BTI text is to entice tourists to visit a place, and even the move Location contributes to the promotion of that purpose.

The above analysis shows that this mixed genre is supposed to undertake the missions of giving information, attracting attention, and enhancing motivation.

Identification of moves and steps. The texts typically consist of two parts: a headline and main text. This analysis of the data leads to the identification of five moves of the online BTI genre. They include: the Headline move, the Background information move, the Establishing credentials move, the Directive information move and the Soliciting response move. The overall structure of moves and steps in the corpus are summarized in Table 1 with descriptions.

The communicative purposes, destination images as well as specific realizations of each move are analyzed with the following excerpts.

\section{Move 1 Headline}

This move type serves the functional purpose of attracting the reader's attention. 26 texts in the corpus have the initiating move showing the name of the tourism destination:

(1) Welcome to Islayinfo - the Ultimate Online Guide to the Isle of Islay

The Isle with a song in its heart and whisky in its soul (Text 3)

In order to achieve the purpose of attracting the reader's attention, this headline extends a welcome to the reader to close the writer-reader relationship and create a hospitable impression on the reader and this favorable impression forms the affective image by "Welcome". What follows is a slogan emphasizing whisky as the unique property and the brand of the destination, which builds the designative image in a parallel structure.

\section{Move 2 Background information}

This move is mainly informative to let the reader know the history of the destination. An example of Move 2 is given below:

(2) This frontier evolved from the first to the fifth centuries $A D$ in response to changing political, social, economic and demographic forces within the Roman Empire and the changing status and role of Britain as an Imperial Province. (Text 9)

History can be a competitive edge, character and culture, of a destination, since history gives it "its colorful past in which a sense of place is sensed" (Durie, 2006:43). As treasure of tourism resources, history is likely to be attractions for some tourists. Therefore, this move also exhibits a slight attracting coloring. When the designative image, the past of the place, is created, the evaluative image is implicitly projected: the place boasts a long history. 
Table 1. A breakdown and description of moves and steps of online BTI texts

\begin{tabular}{|c|c|}
\hline Move and step & Description \\
\hline Move 1 Headline & $\begin{array}{l}\text { A title that serves the functional purpose of attracting readers' } \\
\text { attention and usually shows the name of the tourism destination }\end{array}$ \\
\hline $\begin{array}{l}\text { Move } 2 \text { Background } \\
\text { information }\end{array}$ & $\begin{array}{l}\text { This move type offers information about how long the destination } \\
\text { has come into being, what it was used for, how it was developed to } \\
\text { what it is, etc. }\end{array}$ \\
\hline $\begin{array}{l}\text { Move } 3 \text { Establishing } \\
\text { credentials }\end{array}$ & $\begin{array}{l}\text { This move includes what the writer sees as an advantage for } \\
\text { highlighting the uniqueness of the destination }\end{array}$ \\
\hline $\begin{array}{l}\text { Step } 1 \text { Introducing general } \\
\text { situation }\end{array}$ & $\begin{array}{l}\text { A sketchy description of the destination, mainly for such } \\
\text { information as what the scenic beauty is like, what core attributes } \\
\text { the place possesses, what the major attractions are, etc. }\end{array}$ \\
\hline Step 2 Stating honors & $\begin{array}{l}\text { A brief introduction of the honors or awards the destination wins to } \\
\text { convince readers of the worthiness of going to the place }\end{array}$ \\
\hline $\begin{array}{l}\text { Step } 3 \text { Quoting literary } \\
\text { works }\end{array}$ & $\begin{array}{l}\text { A quotation of legends, anecdotes and some other literatures } \\
\text { related to the destination }\end{array}$ \\
\hline Step 4 Indicating value & $\begin{array}{l}\text { An explicit presentation of archaeological, historical, artistic or } \\
\text { religious values of the place }\end{array}$ \\
\hline $\begin{array}{l}\text { Step } 5 \text { Describing } \\
\text { activities or events }\end{array}$ & $\begin{array}{l}\text { Information about activities or special happenings that are } \\
\text { designed around various themes and that the tourists can } \\
\text { participate to enhance interest of those potential active tourists }\end{array}$ \\
\hline $\begin{array}{l}\text { Step } 6 \text { Describing services } \\
\text { or facilities }\end{array}$ & $\begin{array}{l}\text { Information about the conveniences travelers can enjoy, including } \\
\text { food and accommodation options, sports and entertainment } \\
\text { facilities, etc. }\end{array}$ \\
\hline $\begin{array}{l}\text { Step } 7 \text { Describing key } \\
\text { attractions }\end{array}$ & $\begin{array}{l}\text { Detailed knowledge about the important attractions the destination } \\
\text { boasts, such as natural sceneries, animals, plants, or buildings, } \\
\text { sculptures, etc. to produce a specific profile in the reader's mind }\end{array}$ \\
\hline $\begin{array}{l}\text { Move } 4 \text { Directive } \\
\text { information }\end{array}$ & $\begin{array}{l}\text { Brief directions on how to reach the place and the factual } \\
\text { information about open time or special cautions }\end{array}$ \\
\hline $\begin{array}{l}\text { Move } 5 \text { Soliciting } \\
\text { response }\end{array}$ & Remarks that induce the reader to make response or act \\
\hline Step 1 Soliciting actions & Persuasion to motivate the reader to go to the place \\
\hline $\begin{array}{l}\text { Step } 2 \text { Delivering } \\
\text { welcome/wish/thanks }\end{array}$ & $\begin{array}{l}\text { Welcome, appreciation, or good wish to the reader to establish a } \\
\text { rapport with him }\end{array}$ \\
\hline $\begin{array}{l}\text { Step } 3 \text { Providing contact } \\
\text { details }\end{array}$ & $\begin{array}{l}\text { The information includes address, telephone or fax numbers or } \\
\text { websites to encourage the reader to seek more about the place }\end{array}$ \\
\hline
\end{tabular}

Move 3 Establishing credentials

With the major communicative purposes of informing and attracting, this introductory move is found to be an essential component of the BTI texts because it includes whatever the writer sees as an advantage for attracting the reader's attention. This move can be realized in seven steps as the following descriptions and examples show.

Step 1 Introducing general situation. This step is adopted to help the reader form an impression of its nature and unique attributes. This step focuses on the factual content with descriptive coloring. For example:

(3) Callaway Gardens is a spectacular 13,000 acres of beautiful Georgia countryside in the 
Appalachian Mountains. Home of the world's largest azalea display, one of North America's biggest butterfly conservatories, and magnificent vegetable garden where PBS' "The Victory Garden" is filmed, this Georgia retreat is the perfect destination for family vacations or romantic getaways. (Text 25)

The most conspicuous common lexical feature of the corpus is the frequent use of active, favorable adjectives, which highlights the positive features of the places described and the services offered. In Example (3) the adjectives "spectacular", "beautiful", "magnificent", "perfect" and "romantic" with the superlatives "largest" and "biggest" creates the aura of uniqueness and the evaluative image, luring the reader to believe the garden is worth visiting. The designative image is formed with "13,000 acres", "azalea display", "butterfly conservatories", and "vegetable garden", which inform the reader what resources the destination has.

Step 2 Stating honors. This step intends to make the reader aware of the honors or awards the destination wins to convince him of the worthiness of going to the place and thus serves the communicative purpose of attracting and informing. For instance:

(4) Indeed, the entire city has been designated a World Heritage Site by UNESCO. (Text 11)

In Example (4) the designative image is first built. The referred place has been given the honorable title "World Heritage Site". For a tourism destination, the status of being listed in the program launched by such an authoritative organization as UNESCO is assumed to be a key source of public recognition and credentials. The evaluative image, thus, is implicitly projected: the place is a valuable destination.

Step 3 Quoting literary works. This step is employed to realize the main communicative purpose of attracting the reader's attention and arouse his interest. By quoting legends, anecdotes, and myths about the place, not only is the reader informed that the place is a site of heritage blessed with culture and history, but his curiosity is also likely to be stimulated. For example:

(5) The earliest known reference to the Isle of Islay comes in Adomnan's, Vita Columbae, a biography of the Irish Saint, Columba or Colum Cille in about 720 AD. St Columba visited the Isle of Islay on his way north, prior to founding the famous monastery on the Isle of Iona, off the south-west tip of the Isle of Mull. (Text 3)

In example (5) the mention of the old book makes the reader understand the historical and cultural colorfulness of the destination, furthering its attractiveness and adding to its credential and prestige. Meanwhile, the designative image is projected with the "reference to the Isle of Islay", based on which the evaluative image that the isle is attractive may be created implicitly.

Step 4 Indicating value. As mentioned above, the Introducing general situation step aims at giving a truthful description of the uniqueness of the place whereas the Indicating value step is mainly to appraise the place. This step is adopted to realize the functional purpose of enticing the reader to pay a visit by building a grand image. Through this step archaeological, ecological, historical, artistic, and/or religious values are explicitly presented or summarized. For example:

(6) The nomination for Monticello and the University of Virginia read, "(I) as a unique artistic achievement, a masterpiece of creative genius; (IV) as an outstanding example of a type of a building or architectural ensemble which illustrates a significant stage in history; and (VI) because Monticello and the University of Virginia are directly and tangibly associated with ideas, beliefs, and events of outstanding universal significance." (Text 28)

Obviously the aura of uniqueness and evaluative image is created with the explicit evaluative expressions on the basis of cognitive interpretation of the physical properties of the place, to highlight the destination's values in art, archaeology and human wisdom.

Step 5 Describing activities or events. This step is to create interest of the reader by offering 
information about interesting activities or special happenings that can bring the tourists a pleasant experience. Since sightseeing alone cannot satisfy the novelty or sensation seeking tourists, the introduction of special activities characterized with local customs may arouse their curiosity. For example:

(7) There is a wide variety of festivals and events throughout the year with the summer months being particularly busy. The Folk Festival takes place in May with an impressive line-up of visiting artistes and local musicians performing at concerts, ceilidhs, dances, pub sessions etc over four days. (Text 1)

The designative image is first built by the attractions "festivals and events", "concerts", "ceilidhs", "dances", and "pub sessions". The evaluative image is created by descriptions " $a$ wide variety of", "particularly busy", and "an impressive line-up". Both the two cognitive images contribute to forming the affective image: visiting the place will be pleasant.

Step 6 Describing services or facilities. This step gives information about the conveniences tourists can enjoy, including food and accommodation options, shopping hints, sports and entertainment facilities. It promises the reader a pleasant travel experience. An extensive introduction to all amenities is unaccepted due to the compact nature of the BTI text. An example is as follows:

(8) The Castle now has its own visitor centre, which includes the Ticket Office, Coffee Shop, Gift Shop and toilets. Ample Car parking is available at no charge, and we also welcome large parties and groups. (Text 14)

The designative image is projected by "visitor centre", "Ticket Office", "Coffee Shop", "Gift Shop", "toilets", "Car parking" "at no charge", and "large parties and groups", all of which are related to the tourist experience, which can be heavily influenced by the type and quality of products and services available at a destination (Culter \& Carmichael, 2010). The adjective "ample" helps create the evaluative image to strengthen the reader's impression of the quality service.

Step 7 Describing key attractions. This step describes important attractions the destination boasts, such as landscapes, animals, plants, or buildings, etc. The detailed knowledge is the source that produces a specific profile in the reader's mind and develops his idea of the place. For example:

(9) In addition to the animals, the park is world-renowned for its spectacular orange, yellow, and red foliage in the fall. Although throughout the seasons, wild flowers are in bloom at different altitudes. The park boasts over 1,500 species of native flowering plants, making this a haven for plant lovers of all ages and levels of expertise. (Text 20)

A description of the main attraction forms the designative image of the place with "orange, yellow, and red foliage", "wild flowers" and "1,500 species of native flowering plants". Coupled with the expressions "world-renowned" and "spectacular", metaphor is used here comparing the plants to "a haven for plant lovers" presenting the beautiful scenery before the reader, and thus builds the evaluative image.

What can be seen from the above analysis is that the Establishing credentials move focuses mainly on the designative image and the evaluative image of the destination by giving information about what resources the destination has and evaluation on them.

Move 4 Directive information

This move is to offer brief directions on how to reach the place, and the factual information about open time or special cautions is sometimes given. This is an elective move occasionally embodied in the corpus. An example is given below:

(10) Conducted tours of the Rotunda are offered daily at 10:00am, 11:00am, 2:00pm, 3:00pm and 4:00pm. No admission charge. Self-guided tours only during Thanksgiving, closed 3 weeks 
during Winter Break and during graduation in May. (Text 28)

To fulfill the informing purpose, this move reminds the reader of the important facts about tours at the destination and helps create the designative image with relevant information.

The moves Background information, Establishing credentials, and Directive information have been discussed so far. What should be pointed out about these information-abundant moves is that declarative mood prevails in all the above three moves with the avoidance of the least degree of uncertainty by the absence of any modality, projecting a sense of authority. The simple present tense, coupled with occasional use of personal pronoun, makes the texts settled and detached from human influence, and highlights the reliability of the information offered.

\section{Move 5 Soliciting response}

This move induces the reader to make response or take action. It can be realized by the following three steps:

Step 1 Soliciting actions. This step is to persuade or motivate the reader to buy the tourist product. For instance:

(11) Experience Britain's greatest Roman monument: 2,000 years in the making, just minutes in the booking. (Text 9)

The employment of various figures of speech can achieve persuasiveness and entice the reader, and in Example (11) not only does the imperative mood create a feeling of urgency to make a reservation for going to the monument but the use of antithesis and rhyme also emphasizes the convenience of making a booking. Thus, the focus of this step is to generate the evaluative image: it is convenient to make a reservation, with "just minutes in the booking".

Step 2 Delivering welcome/wish/thanks. This step is designed to give an end (sometimes a beginning) to the text, helping establish a rapport with the addressee, impressing him with hospitality and sincerity, and more importantly persuading him to pay a visit. For example:

(12) We look forward to welcoming you to Britain's Greatest Palace very soon. (Text 4)

The second person pronoun "you" is often used to address the reader so as to effect an interpersonal tone. According to Henry and Roseberry (1996), the reader is addressed by "you" to create an informal friendly personal tone. Zhu (2000) pointed out that the "you" approach by placing readers at the center of attention could win their cordial fellowship and that the "we" approach could show the writer's willing attitude to do something. In Example (12) "you" and "we" work as persuasive device helping alleviate the writer's authoritative status based on his expert knowledge about the place and to stress a conversational and informal style. A hospitable and friendly impression is strengthened with "welcome", building the affective image.

Step 3 Providing contact details. This step is employed to encourage the reader to find out more about the place. It offers the contact details, which can be used by the reader to enter into contact with or get more information about the destination. For example:

(13) To learn more about exploring the park or to begin planning your vacation to Niagara Falls, NY, use the navigation on the left or call (716) 278-1796. (Text 27)

In this example, interpersonal tone is enhanced by the use of the imperative, a device to create a pseudodialogue between the addresser and the addressee, urging the reader to take actions as the writer expects.

The genre of BTI text has been broken down into moves and steps, which also reveals how various discursive strategies and linguistic devices contribute to the realization of these moves and destination images. To present an overall description, a sample analysis of the structural moves and constituent steps has been provided in Appendix 2.

Move structures. The move structures of the English BTI texts will be analyzed in terms of 
move frequency and move recursion.

Move frequency. The BTI texts of the corpus have two to five moves. A closer examination of the occurrence frequency of the moves shows that Move 3 (Establishing credentials) occurs at least once in all of the texts, indicating that it is an obligatory move type. The remaining moves occur in only some of the texts and fulfill a satellite communicative function as optional moves.

Table 2 illustrates the percentages of occurrence of the moves in the corpus. It can be seen from the statistics that Move 3 occurs in all the 30 texts and thus constitutes the nuclear category of English BTI text. Move 1 (Headline) and Move 5 (Soliciting response) appear frequently, with $87 \%$ and $80 \%$ in the corpus. The texts are characterized with the low occurrence frequency of Move 4 (Directive information) with $17 \%$ in the corpus.

Table 2. Patterns of occurrence of moves and steps in BTI texts

\begin{tabular}{|c|c|c|}
\hline \multirow{2}{*}{ Move and step } & \multicolumn{2}{|c|}{ BTI texts containing move and step } \\
\hline & Number $\quad \mathrm{N}=30$ & Percent of total texts \\
\hline Move 1 Headline & 26 & $87 \%$ \\
\hline Move 2 Background information & 13 & $43 \%$ \\
\hline Move 3 Establishing credentials & 30 & $100 \%$ \\
\hline Move 4 Directive information & 5 & $17 \%$ \\
\hline Move 5 Soliciting response & 24 & $80 \%$ \\
\hline
\end{tabular}

Move sequence and recursion. A closer look at where the moves occur in the texts shows that Move 1 (Headline) always occurs first in the texts, and Move 2 (Background information) and Move 3 (Establishing credentials) usually appear in the middle of the texts. Move 4 (Directive information) can occur at multiple places, including at the middle of Move 2 and Move 3, or right after Moves 2 and 3. Generally, Move 5 (Soliciting response) can be found at the end of the texts.

Individual moves can recur within a section of text. According to Biber, Connor and Upton (2007), each appearance of a particular move should be counted as a separate occurrence, and therefore, a single move can appear multiple times. Adopting this approach to identify and count moves, we can find that move recursion frequently occurs in the corpus with Move 3 (Establishing credentials) and this move is sometimes interpolated with other moves.

Table 3. Move totals and percentages

\begin{tabular}{lcc}
\hline \multirow{2}{*}{ Moves } & \multicolumn{2}{c}{ BTI texts } \\
\cline { 2 - 3 } & Total number of moves & Percent of total moves \\
\hline Move 1 Headline & 26 & $17.8 \%$ \\
Move 2 Background information & 15 & $10.3 \%$ \\
Move 3 Establishing credentials & 55 & $37.7 \%$ \\
Move 4 Directive information & 9 & $6.2 \%$ \\
Move 5 Soliciting response & 41 & $28 \%$ \\
Total & 146 & $100 \%$ \\
\hline
\end{tabular}

Table 3 provides the total number of each move identified in the corpus and the percentage of each move type in all the moves. Not surprisingly, the most commonly occurring move type in all the texts is Move 3, which occurs 55 times. This move type represents $37.7 \%$ of all the moves occurring in the corpus, showing up at the average rate of nearly twice per text. What follows is Move 5 (Soliciting response), which occurs 1.37 times per text at $28 \%$ in the corpus.

\section{Discussion}

The study approaches the English BTI texts on websites of tourism destinations within the 
framework of genre analysis. The major findings can be summarized as follows:

First, BTI texts are a mixed genre exhibiting a mixed feature of being informative, attractive and persuasive. The three purposes are closely interwoven and the boundary between them is rather vague. Genre mixing cases were explored by Bhatia (1993), who found that the informative purposes were usually colonized by promotional goals in many cases in which describing a product or service is done in a positive way. Similarly, each structural move of BTI texts may fulfill one or two major functions, but it has to be contributory to the promotional goal.

Second, the move Establishing credentials is found the only obligatory move of BTI texts. This can be seen by the fact that it not only occurs in every text in the corpus, but it also appears nearly twice in each text. The other three move types, Move Background information, Move Headline, and Move Soliciting response clearly serve as important tools in the genre as they are included in a sizable percentage of the texts. The move Directive information noticeably plays a secondary role in the genre.

Third, the most conspicuous lexical feature of Move Establishing credentials is the frequent use of favorable adjectives, which highlights the positive features of the places described and the services offered. The sense of authority and reliability of the information is mainly realized through the domination of the declarative in the simple present tense in the moves Establishing credentials, Background information and Directive information. Move Soliciting response, however, foregrounds an interpersonal tone and adds some communicative element to the genre with the use of personal pronoun "you" addressing the reader with occasional employment of the imperative.

Fourth, the designative image is mainly created by the names of all kinds of destination resources in the information-abundant moves Establishing credentials, Background information and Directive information. The evaluative image is built most of the time in an explicit way in the moves Establishing credentials, Background information and Soliciting response through extensive use of evaluative adjectives. The affective image, apparent in Move Soliciting response, is mainly induced from the designative and evaluative images.

\section{Conclusion}

Based on the previous analyses and discussions, a tentative conclusion can be drawn about the genre of BTI text and the destination images it projects.

(1) The Establishing credentials move plays a crucial role in introducing and promoting the referred tourism destinations and constitutes the obligatory move in BTI texts. This implies that giving information is the essential function of BTI texts though the information is sometimes "one-sided" with positive evaluations. Accordingly, it is the Establishing credentials move that mainly builds the designative image and evaluative image, both of which act as the basic dimensions of the affective image, planting the destination character in readers' mind.

(2) BTI texts exhibit a balance between two prominent tones: the tone of authority and the interpersonal tone. The dominant tone of authority and impersonality of the introductory moves is alleviated by the interpersonal tone of Move Soliciting response, which contributes to the establishment of the affective image, a mediator in projecting the destination image, arousing positive feelings in readers.

In summary, not only is the genre of BTI texts a medium to deliver tourist information, but also a bridge between destination resources and tourist experience, depicting unique destination image. 


\section{References}

[1] S. Baloglu, and K. McCleary, A model of destination image formation, Annals of Tourism Research 26 (1999) 868-897.

[2] V.K. Bhatia, Analysing Genre: Language use in professional settings, Longman, London, 1993.

[3] D. Biber, U. Connor, and T.A. Upton, Discourse on the Move: Using corpus analysis to describe discourse structure, John Benjamins, Amsterdam, 2007.

[4] S.Q. Culter, and B.A. Carmichael, The Dimensions of the Tourist Experience, in: M. Morgan, P. Lugosi, and J.R. B. Ritchie, (Eds.) The tourism and leisure experience: Consumer and managerial perspectives, Channel View Publications, Bristol, 2010, 3-26.

[5] B. Dicks, Culture on Display: The production of contemporary visitability, Peking University Press, Beijing, 2007.

[6] A. Durie, I.S. Yeoman, and U. McMahon-Beattie, How the history of Scotland creates a sense of place, Place Branding 2 (1) (2006) 43-52.

[7] J. Flowerdew, The Discursive Construction of a World-Class City, Discourse and Society 15 (2004) 579-605.

[8] A. Henry, and R. L. Roseberry, A corpus-based investigation of the language and linguistic patterns of one genre and the implications for language teaching, Research in the Teaching of English 30 (4) (1996) 472-489.

[9] W. Lin, and Y. Yang, English Discourse Analysis, Fudan University Press, Shanghai, 2007.

[10] G. Richards and J. Wilson, The impact of cultural events on city image: Rotterdam, cultural capital of Europe 2001, Urban Studies 41 (2004) 1931-1951.

[11] J.M. Swales, Genre Analysis: English in academic and research settings, Cambridge University Press, Cambridge, 1990.

[12] C. Thurlow, and A. Jaworski, Tourism Discourse: Language and global mobility, Palgrave Macmillan, Hampshire and New York, 2010.

[13] H. Zhang, F. Xu, L. Lu, and Y. Lei, Cultural Capital and Destination Image of Metropolitans: A comparative study of New York and Tokyo official tourism websites in Chinese, Journal of China Tourism Research 11:2 (2015) 121-149.

[14] Y. Zhu, Structural moves reflected in English and Chinese sales letters, Discourse Studies 2 (2000) 473-496.

\section{Appendix 1. Sources of the selected texts}

\begin{tabular}{rlll}
\hline Text & \multicolumn{1}{c}{ Website } & Text & \multicolumn{1}{c}{ Website } \\
\hline Text 1 & http://www.visitorkney.com & Text 16 & http://www.visittemplesquare.com \\
Text 2 & http://www.giantscausewayofficialguide.com & Text 17 & http://www.huntingisland.com \\
Text 3 & http://islayinfo.com & Text 18 & http://www.navypier.com \\
Text 4 & http://www.blenheimpalace.com & Text 19 & http://www.golden-gate-park.com \\
Text 5 & http://www.visitgreenwich.org.uk & Text 20 & http://www.smokymountainvacationinfo.com \\
Text 6 & http://www.newlanark.org & Text 21 & http://web.miamibeachfl.gov \\
Text 7 & http://www.world-heritage-blaenavon.org.uk & Text 22 & http://www.yosemitepark.com \\
Text 8 & http://www.snowdon.com & Text 23 & http://www.yellowstonenationalpark.com \\
Text 9 & http://www.hadrians-wall.org & Text 24 & http://www.mesaverde.com \\
Text 10 & http://www.visitpiccadilly.com & Text 25 & http://www.callawaygardens.com \\
Text 11 & http://visitbath.co.uk & Text 26 & http:///royalgorgebridge.com \\
\hline
\end{tabular}




\begin{tabular}{clcl}
\hline Text & \multicolumn{1}{c}{ Website } & Text & \multicolumn{1}{c}{ Website } \\
\hline Text 12 & http://www.ironbridge.info & Text 27 & http://www.niagarafallsstatepark.com \\
Text 13 & http://www.altontowers.com & Text 28 & http://www.visitcharlottesville.org \\
Text 14 & http://www.eileandonancastle.com & Text 29 & http://www.papahanaumokuakea.gov \\
Text 15 & http://www.visitlochness.com & Text 30 & http://pinemountain.org \\
\hline
\end{tabular}

\section{Appendix 2. A demonstrative move analysis of the BTI text for Text 14}

Move Headline

Welcome to Eilean Donan castle

Move Establishing As one of the most iconic images of Scotland, Eilean Donan is recognised all around credentials: Step the world. Situated on an island at the point where three great sea lochs meet, and Introducing surrounded by some majestic scenery, it is little wonder that the castle is now one of general situation the most visited and important attractions in the Scottish highlands.

Although first inhabited around the 6th century, the first fortified castle was built in the mid 13th century and stood guard over the lands of Kintail. Since then, at least four different versions of the castle have been built and re-built as the feudal history of Scotland unfolded through the centuries.

Partially destroyed in a Jacobite uprising in 1719, Eilean Donan lay in ruins for the Move Background best part of 200 years until Lieutenant Colonel John MacRae-Gilstrap bought the information island in 1911 and proceeded to restore the castle to its former glory. After 20 years of toil and labour the castle was re-opened in 1932.

Move Establishing Today, you can explore nearly every part of the castle, and enjoy a journey through credentials: Step the history of the area.

Introducing
general situation Shop, Gift Shop and toilets.

Move Establishing Ample Car parking is available at no charge, and we also welcome large parties and credentials: Step groups.

Describing Although we have no disabled or wheelchair access into the castle itself, we do have a services or computer-based Virtual Tour available for those that are unable to manage the large facilities number of steps. Please ask at the visitor centre if you require this facility.

Move Soliciting

Some people say Eilean Donan is the most beautiful castle in Scotland. Come and

response: Step decide for yourself!

Soliciting actions 